\title{
First-Principle Calculation of Structural, Mechanical, Electronic and Magnetic Properties of Cobalt Sub Hydrides $\mathrm{CO}_{2} \mathrm{H}$ and $\mathrm{Co}_{3} \mathrm{H}$
}

\author{
Merabet $\mathbf{N}^{1}$, Riane $\mathbf{R}^{2 *}$ and Abdiche $\mathrm{A}^{2}$ \\ ${ }^{1}$ Modeling and Simulation Laboratory of Sidi-Belabes, 22000 Sidi-Belabes, Algeria \\ ${ }^{2}$ Science and Technology Department, University of Ibn Khaldoun, Tiaret, Algeria
}

\begin{abstract}
In this present work, we perform first-principles calculations of the structural, electronic, mechanical and mechanical properties of Cobalt sub-hydrides $\left(\mathrm{CO}_{2} \mathrm{H}\right.$ and $\left.\mathrm{Co}_{3} \mathrm{H}\right)$ based on the density functional theory with local spin density (LSDA), and generalized gradient (GGA) approximations.

The optimized structural parameters, densities of states, elastic constants $\left(C_{i j}\right)$ and mechanical properties (Young's modulus $\mathrm{Y}$, Shear modulus $\mathrm{G}$, Poisson's ratio v) were obtained for the first time and analyzed.

Our calculation shows that the insertion of hydrogen in low-concentration into cobalt leads to the expansion of unit cell volume and the bulk modulus as a function of this concentration. A resulting strong reduction of magnetization characterizes these subs-hydrides.
\end{abstract}

Keywords: Cobalt sub-hydrides; DFT; FP-LAPW; Elastic constant; Magnetic properties

\section{Introduction}

Hydrogen has several interesting characteristics that could make it one of the energy carriers of the future. It has a mass energy density three times higher than that of diesel. Hydrogen can only play its role as an energy carrier if it can be stored efficiently, cheaply and under acceptable safety conditions. At room temperature and atmospheric pressure, hydrogen is in the form of a very volatile gas, because of the small size of its molecule. The challenge is to create compact and lowcost reservoirs.

Finally, a more recent line of research focuses on the use of materials called hydrides that have the ability to absorb and desorb hydrogen in a reversible manner, under temperature conditions ("solid" storage). Storage in hydrides is the most efficient way to obtain a high density of energy. But this is done at the expense of weight, since we must add to the balance sheet the weight of the material in which the hydrogen is inserted.

The metal hydrides are formed by solid-gas reaction, from metals or intermetallic compounds able to form reversible bonds with hydrogen.

The importance of $\mathrm{H}$-metal transition bonds led to theoretical and experimental studies in the fields of surface science [1], catalysis [2-5] and organic chemistry [6]. The metals $\mathrm{Cr}, \mathrm{Mo}, \mathrm{Mn}, \mathrm{Tc}, \mathrm{Re}, \mathrm{Fe}$ and Co were found to form hydrides based on an hcp metal lattice [7].

A lot of research studying cobalt and are confirmed that the Hcp Co is the stable form at ambient conditions [8,9] And under a pressure of $105 \mathrm{GPa}$, a phase transition has been observed from the magnetic hcp Co to a $\beta$-fcc phase (likely nonmagnetic) [10].

The design of new materials and the understanding of their properties require fundamental knowledge of their structures, phase stability, and various structural, electronic and mechanical properties and understanding the behavior of hydrogen in the host matrix is a fundamental interest in the study of hydrides, to understand the changes in physical properties provided by $\mathrm{H}$. To the best of our knowledge there are no theoretical exhaustive investigations of $\mathrm{Co}-\mathrm{H}$ with low $\mathrm{H}$ concentrations, i.e. subhydrides.
In this paper, we present first principles calculations for studying the structural, mechanical, electronic, magnetic properties of subhydrides $\left(\mathrm{Co}_{3} \mathrm{H}, \mathrm{Co}_{2} \mathrm{H}\right)$.

Parallel calculations for hcp $\mathrm{Co}$ and $\mathrm{CoH}$ were performed in order to enable comparison of the electronic structures of $\mathrm{Co}_{2} \mathrm{H}$ and $\mathrm{Co}_{3} \mathrm{H}$ host metal.

\section{Computation Methods}

The first-principles calculations were performed by employing the full potential linearized augmented plane wave method (FP-LAPW) approach based on the density functional theory (DFT) [11] and implemented in the WIENK code [12].

The exchange-correlation potential is treated within the generalized gradient approximation of Perdew Burke Ernzerhof (GGA-PBE) [13] and the local spin density approximation of the Perdew and Wang (LSDA) [14].

The plane-wave expansion was taken to $R \mathrm{MT} \times \mathrm{KMAX}$ equal to 7 , and the $k$ sampling with $14 \times 14 \times 4 k$-points in the Brillouin zone was used. The calculations were performed with full-lattice optimization. For Co we adopted a value of 1.75 and a value of 1.1 Bohr for Hydrogen $\mathrm{H}(1 \mathrm{Bohr}=0.529 \AA)$, as the muffin tin MT radii [15].

We have distinguished the Co $\left(1 s^{2} 2 s^{2} 2 p^{6} 3 s^{2}\right)$ inner-shell electrons from the valence electrons of Co $\left(3 \mathrm{p}^{6} 3 \mathrm{~d}^{7} 4 \mathrm{~s}^{2}\right), H\left(1 s^{1}\right)$ shells.

In this work Hexagonal-elastic software [16] is used to calculate the elastic properties of the four systems. The energy approach [17] as implemented in the WIEN2k [12] is used to obtain reliable results.

*Corresponding author: Riane Rabah, Science and Technology Department University of Ibn Khaldoun, Tiaret, Algeria, Tel: 213-783082649; E-mail rianerab@yahoo.fr

Received May 31, 2018; Accepted June 20, 2018; Published June 30, 2018

Citation: Merabet N, Riane R, Abdiche A (2018) First-Principle Calculation of Structural, Mechanical, Electronic and Magnetic Properties of Cobalt Sub Hydrides $\mathrm{Co}_{2} \mathrm{H}$ and $\mathrm{Co}_{3} \mathrm{H}$. J Material Sci Eng 7: 463. doi: 10.4172/2169-0022.1000463

Copyright: (c) 2018 Merabet N, et al. This is an open-access article distributed under the terms of the Creative Commons Attribution License, which permits unrestricted use, distribution, and reproduction in any medium, provided the original author and source are credited. 


\section{Results and Discussion}

\section{Structural properties}

With the purpose of evaluating the hydrogen insertion effects on the electronic structure of Cobalt, two Cobalt sub-hydrides configurations were considered for different concentrations of hydrogen namely respectively $\mathrm{Co}_{3} \mathrm{H}$ (p63mc (186)), $\mathrm{Co}_{2} \mathrm{H}\left(\mathrm{P} \_3 \mathrm{ml}(164)\right)$. And we studied Co (p63 mmc (194)) and $\mathrm{CoH}$ (p63 mmc (194)) for compared.

Firstly, we optimized the structural parameters like lattice constant $\mathrm{a}_{0}$ and $\frac{c}{a}$, the bulk modulus and its pressure derivative for $\mathrm{Co}, \mathrm{Co}_{3} \mathrm{H}$, $\mathrm{Co}_{2} \mathrm{H}$ and $\mathrm{CoH}$ systems. These parameters are predicted by optimizing the volume, i.e. minimizing the total energy of the unit cell with respect to the variation in its volume.

The unit cell energy versus volume plots for the four configurations are shown in Figure 1 give the minimum position of the equation of state (EOS) [18].

The values of structural parameters like lattice constant, bulk modulus, the pressure derivative of bulk modulus and the unit cell volume as well as energy for compact hexagonal phases within PBEGGA and LSDA exchange-correlation are given in Table 1 and are in reasonable agreement with the available experiments and theoretical calculations.

In this calculation, we considered a number of configurations for the insertion of hydrogen into cobalt. Our results show that this insertion with different hydrogen concentrations has the effect of increasing the volume of the unit cell and the bulk modulus.

\section{Elastic properties}

The elastic properties of solids are important because they relate to different basic solid-state properties like brittleness, ductility and anisotropy. Practical applications related to the mechanical properties of solids such as load flexion, thermo elastic stress, internal deformation, sound velocities and fracture toughness require knowledge of elastic constants [19-23]. In addition, the elastic constants give the relation between the mechanical and dynamic properties with regard to the forces present in the solids. We know that there are five independent elastic constants for hexagonal symmetry, called $C_{11}, C_{12}, C_{13}, C_{33}$ and $C_{44}[24]$.

Our calculated values for $\mathrm{Co}, \mathrm{Co}_{3} \mathrm{H}, \mathrm{Co}_{2} \mathrm{H}$ and $\mathrm{CoH}$ systems at ambient pressure are listed in Table 2.

For hexagonal systems, criteria for mechanical stability the $C_{i}$ constants for all systems studied are positive and satisfy the BornHuang criteria [25]:

$$
C_{12}>0, C_{33}>0, C_{66}=\left(C_{11}-C_{12}\right)>0, C_{44}>0,\left(C_{11}+C_{12}\right)\left(C_{33}{ }^{2}-2 C_{13}{ }^{2}\right)>0,
$$

The agreement of elastic constants calculated for cobalt with experimental results without pressure is excellent with a mean squared error of less than $20 \mathrm{GPa}$. Therefore the $\mathrm{CoH}, \mathrm{Co}_{2} \mathrm{H}$ and $\mathrm{Co}_{3} \mathrm{H}$ hexagonal structures are mechanically stable, knowing that we do not have experimental data on elasticity properties and we hope that future experimental measurements will test our calculated predictions.

\section{Mechanical properties}

We can determined the mechanical properties from the elastic constants like the isotropic bulk modulus (B), shear modulus (G), Young's modulus (Y), anisotropic ratio (A), Poisson's ratio $(v)$, and the compressibility .

To estimate these properties, foremost two schemes of approximations are typically used, that are Voigt (V) [26] and
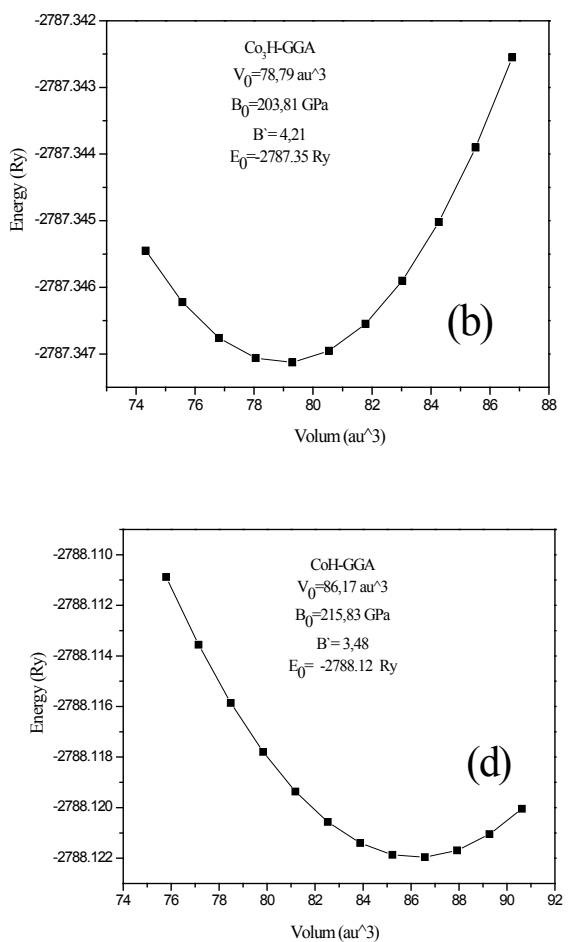

Figure 1: Energy as function of volume for $\mathrm{Co}(\mathrm{a}), \mathrm{Co}_{3} \mathrm{H}(\mathrm{b}), \mathrm{Co}_{2} \mathrm{H}(\mathrm{c})$ and $\mathrm{CoH}(\mathrm{d})$ in $\mathrm{GGA}$ DFT functional. Inserts show fit values from Murnaghan EOS. 
Citation: Merabet N, Riane R, Abdiche A (2018) First-Principle Calculation of Structural, Mechanical, Electronic and Magnetic Properties of Cobalt Sub Hydrides $\mathrm{Co}_{2} \mathrm{H}$ and $\mathrm{Co}_{3} \mathrm{H}$. J Material Sci Eng 7: 463. doi: 10.4172/2169-0022.1000463

Page 3 of 7

\begin{tabular}{|c|c|c|c|c|c|c|}
\hline \multirow{2}{*}{$\begin{array}{l}\text { Compound (structure type; } \\
\text { space group) }\end{array}$} & & \multicolumn{2}{|c|}{ This work } & \multicolumn{2}{|c|}{ Other theoretical studies } & \multirow[t]{2}{*}{ Experimental Data } \\
\hline & & GGA & LSDA & GGA & LSDA & \\
\hline $\begin{array}{c}\text { Co } \\
\text { Hcp } \\
\mathrm{p}_{3} / \mathrm{mmc}(\# 194)\end{array}$ & $\begin{array}{c}\mathrm{a}\left(\mathrm{A}^{\circ}\right) \\
\mathrm{c} / \mathrm{a} \\
\mathrm{V}_{0} \\
\mathrm{~B}_{0}(\mathrm{GPa}) \\
\mathrm{B}^{\prime}(\mathrm{GPa}) \\
\mathrm{E}_{0}\end{array}$ & $\begin{array}{c}2.49 \\
1.62 \\
73.13 \\
195.83 \\
3.45 \\
-2786.89 \\
\end{array}$ & $\begin{array}{c}2.42 \\
1.60 \\
67.19 \\
- \\
4.26 \\
-2782.29\end{array}$ & $\begin{array}{c}2.51[9] \\
1.6215[9] \\
73.6[21] \\
212[21], 259.35[9] \\
4.2[21] \\
-2786.7364[21]\end{array}$ & $\begin{array}{c}- \\
- \\
68.0[21] \\
255[21] \\
4[21] \\
-2782.1081[21]\end{array}$ & $\begin{array}{c}2.51[19,20] \\
1.6215[19,20] \\
74.9[22] \\
190[22] \\
3.6[22] \\
-\end{array}$ \\
\hline $\begin{array}{c}\mathrm{Co}_{3} \mathrm{H} \\
\mathrm{Hcp} \\
\mathrm{P}_{3} / \mathrm{mc}(\# 186)\end{array}$ & $\begin{array}{c}\mathrm{a}\left(\mathrm{A}^{\circ}\right) \\
\mathrm{c} / \mathrm{a} \\
\mathrm{V}_{0} \\
\mathrm{~B}_{0}(\mathrm{GPa}) \\
\mathrm{B}^{\prime}(\mathrm{Gpa}) \\
\mathrm{E}_{0}\end{array}$ & $\begin{array}{c}2.56 \\
1.60 \\
78.79 \\
203.81 \\
4.21 \\
-2787.35\end{array}$ & $\begin{array}{c}2.49 \\
1.60 \\
72.39 \\
254.11 \\
4.25 \\
-2782.67\end{array}$ & 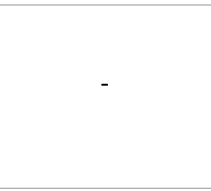 & 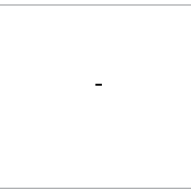 & 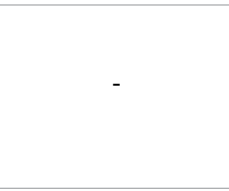 \\
\hline $\begin{array}{c}\mathrm{Co}_{2} \mathrm{H} \\
\mathrm{Hcp} \\
\mathrm{P}_{-} 3 \mathrm{~m} 1(\# 164)\end{array}$ & $\begin{array}{c}\mathrm{a}\left(\mathrm{A}^{\circ}\right) \\
\mathrm{c} / \mathrm{a} \\
\mathrm{V}_{0} \\
\mathrm{~B}_{0}(\mathrm{GPa}) \\
\mathrm{B}^{\prime}(\mathrm{GPa}) \\
\mathrm{E}_{0}\end{array}$ & $\begin{array}{c}2.58 \\
1.59 \\
80.34 \\
209.26 \\
5.23 \\
-2787.54\end{array}$ & $\begin{array}{c}2.52 \\
1.59 \\
74.16 \\
254.11 \\
4.25 \\
-2782.89\end{array}$ & - & - & - \\
\hline $\begin{array}{c}\mathrm{CoH} \\
\mathrm{Hcp} \\
\mathrm{p} 6_{3} / \mathrm{mmc}(\# 194)\end{array}$ & $\begin{array}{c}\mathrm{a}\left(\mathrm{A}^{\circ}\right) \\
\mathrm{c} / \mathrm{a} \\
\mathrm{V}_{0} \\
\mathrm{~B}_{0}(\mathrm{GPa}) \\
\mathrm{B}^{\prime}(\mathrm{GPa}) \\
\mathrm{E}_{0}\end{array}$ & $\begin{array}{c}2.62 \\
1.63 \\
86.17 \\
215.83 \\
3.48 \\
-2788.12\end{array}$ & $\begin{array}{c}2.55 \\
1.64 \\
79.8914 \\
255.1252 \\
4.4348 \\
-2783.47\end{array}$ & - & - & - \\
\hline
\end{tabular}

Table 1: Lattice constants a, c/a ratio, bulk modulus $\mathrm{B}_{0}$, and pressure derivative of bulk modulus $\mathrm{B}^{\prime}$ for $\mathrm{Co}, \mathrm{Co}_{3} \mathrm{H}, \mathrm{Co}_{2} \mathrm{H}$ and $\mathrm{CoH}$ solid solutions.

\begin{tabular}{|c|c|c|c|c|c|c|c|c|}
\hline & \multicolumn{2}{|r|}{ Co } & \multicolumn{2}{|r|}{$\mathrm{Co}_{3} \mathrm{H}$} & \multicolumn{2}{|r|}{$\mathrm{Co}_{2} \mathrm{H}$} & \multicolumn{2}{|c|}{$\mathrm{CoH}$} \\
\hline & Our work & $\begin{array}{l}\text { Experimental data } \\
{[22]}\end{array}$ & Our work & Experimental data & Our work & Experimental data & Our work & Experimental data \\
\hline$C_{11}$ & 352 & 325 & 209 & I & 450 & 1 & 308 & I \\
\hline $\mathrm{C}_{12}$ & 139 & 165 & 99 & 1 & 129 & 1 & 226 & 1 \\
\hline $\mathrm{C}_{13}$ & 86 & 102 & 148 & 1 & 149 & 1 & 181 & 1 \\
\hline $\mathrm{C}_{33}$ & 358 & 357 & 579 & 1 & 411 & 1 & 392 & 1 \\
\hline $\mathrm{C}_{55}$ & 94 & 75 & 134 & I & 127 & I & 112 & I \\
\hline
\end{tabular}

Table 2: Calculated elastic constants ( $\mathrm{Cij}$, in $\mathrm{GPa}$ ) of hcp-Co and hexagonal Cobalt sub-hydrides in comparison with available experimental and theoretical data.

Reuss (R) [27]. In addition, for the polycrystalline materials, elastic parameters are also estimated by employing Voigt-Reuss-Hill (VRH) approximation [28]:

$$
\begin{aligned}
& B_{H}=\frac{1}{2}\left(B_{V}+B_{R}\right) \\
& G_{H}=\frac{1}{2}\left(G_{V}+G_{R}\right)
\end{aligned}
$$

While for the hexagonal systems, the $B$ and $G$ values in terms of the Voigt approximation are expressed as:

$$
\begin{aligned}
& B_{V}=\frac{1}{9}\left\{2\left(C_{11}+C_{12}\right)+4 C_{13}+C_{33}\right\} \\
& G_{V}=\left(\frac{1}{30}\right)\left\{C_{11}+C_{12}+2 C_{33}-4 C_{13}+12 C_{44}+12 C_{66}\right\}
\end{aligned}
$$

And in terms of the Reuss approximation as:

$$
\begin{aligned}
& B_{R}=\left\{\left(C_{11}+C_{12}\right) C_{33}-2 C_{12}{ }^{2}\right\} /\left(C_{11}+C_{12}+2 C_{33}-4 C_{13}\right) \\
& G_{R}=\frac{\left\{\frac{5}{2}\right\}\left\{\left[\left(C_{11}+C_{12}\right) C_{33}-2 C_{12}^{2}\right] C_{55} C_{66}\right\}}{\left\{3 B_{V} C_{55} C_{66}\left[\left(C_{11}+C_{12}\right) C_{33}-2 C_{12}{ }^{2}\right]^{2}\left(C_{55}+C_{66}\right)\right\}}
\end{aligned}
$$

We also calculated the Young's modulus (Y), and Poisson's ratio $(v)$, which are frequently measured for polycrystalline materials when investigating their hardness. These quantities are related to the bulk modulus B and the shear modulus $\mathrm{G}$ by the following equations [29]:

$$
\begin{aligned}
& Y=\frac{9 B G}{(3 B+G)} \\
& v=\frac{(3 B-E)}{6 B}
\end{aligned}
$$

Bulk modulus calculation is given for hexagonal crystals as the combination of elastic constants:

$$
B=\left[\mathrm{C}_{33}\left(\mathrm{C}_{11}+\mathrm{C}_{12}\right)-2 \mathrm{C}_{13}^{2}\right] / C_{11}+C_{12}+2 C_{33}-4 C_{13}
$$

One of the standard methods to calculate the Debye temperature is from elastic constants data, since $\theta_{D}$ may be estimated from the average sound velocity $v_{\mathrm{m}}$, from the following equation [30,31]:

$$
\theta_{D}=\frac{h}{k_{B}}\left[\frac{3}{4 \pi v_{a}}\right]^{\frac{1}{3}} v_{m}
$$

Where $\mathrm{h}$ is Planck's constant, $\mathrm{k}_{\mathrm{B}}$ is Boltzmann's constant, and $v_{\mathrm{a}}$, average atomic volume, $v_{\text {, }}$ is obtained from $[30,31]$ :

$$
v_{m}=\left[\frac{1}{3}\left(\frac{2}{v_{s}^{3}}+\frac{1}{v_{l}^{3}}\right)\right]^{-1 / 3}
$$

Where $v_{\mathrm{s}}$ and $v_{l}$ are the transverse and longitudinal sound velocities in an isotropic material. These can be obtained from the density $\rho$, the shear modulus and the bulk modulus using Navier's equation[30,32] : 


\begin{tabular}{|c|c|c|c|c|c|c|c|c|}
\hline & $\mathbf{B}(\mathbf{G P a})$ & $\mathbf{G v}(\mathbf{G P a})$ & $\mathbf{Y}(\mathbf{G P a})$ & $\mathbf{v}$ & $\mathbf{v}_{\mathbf{s}}(\mathbf{m} / \mathbf{s})$ & $\mathbf{v}_{\mathbf{1}}(\mathbf{m} / \mathbf{s})$ & $\mathbf{v}_{\mathbf{m}}(\mathbf{m} / \mathbf{s})$ & $\boldsymbol{\theta}_{\mathbf{D}}(\mathbf{K})$ \\
\hline $\mathrm{Co}$ & 187.20 & 108.88 & 273.60 & 0.256 & 3450.84 & 6047.75 & 3834.98 & 515.95 \\
\hline $\mathrm{Co}_{3} \mathrm{H}$ & 198.45 & 104.85 & 267.46 & 0.275 & 3337.78 & 5976.86 & 3715.93 \\
\hline $\mathrm{Co}_{2} \mathrm{H}$ & 240.30 & 142.034 & 355.97 & 0.253 & 4127.31 & 7189.76 & 4584.38 \\
\hline $\mathrm{CoH}$ & 242.63 & 80.80 & 218.168 & 0.350 & 3057.66 & 6599.64 & 3443.99 & 552.716 \\
\hline
\end{tabular}

Table 3: The calculated Bulk modulus, Shear modulus, Young modulus, Poisson coefficient, Transverse elastic wave velocity, longitudinal elastic wave velocity, the average wave velocity and Debye temperature for $\mathrm{Co}, \mathrm{Co}_{3} \mathrm{H}, \mathrm{Co}_{2} \mathrm{H}$ and $\mathrm{CoH}$ solid solutions.

$$
v_{l}=\left[\frac{B_{0}+\frac{4 G}{3}}{\rho}\right]^{\frac{1}{2}} \text { and } v_{s}=\left[\frac{G}{\rho}\right]^{\frac{1}{2}}
$$

We classified also, the calcula with voight approximation of Bulk modulus, Shear modulus, Young modulus, Poisson coefficient, Transverse elastic wave velocity, longitudinal elastic wave velocity, the average wave velocity and Debye temperature for $\mathrm{Co}, \mathrm{Co}_{2} \mathrm{H}, \mathrm{Co}_{3} \mathrm{H}$ and $\mathrm{CoH}$ solid solutions in the Table 3 , we can see that the values of the Bulk modulus computed from the elastic constants have values close to those obtained from the EOS adjustment, and the compatibility between the two methods in the ascending evolution of Bulk modulus for the $\mathrm{Co}, \mathrm{Co}_{2} \mathrm{H}, \mathrm{Co}_{3} \mathrm{H}$ and $\mathrm{CoH}$ systems respectively. This could be an estimate of the reliability and precision of our calculated elastic constants for the compounds.

Based on our results, $B>G$ for all systems examined; this implies that the parameter limiting the mechanical stability of these materials is the shear modulus. The factors B (which measures the resistance to volume change with invariable proportions) and $\mathrm{G}$ (which measures the resistance to shear deformation) [33-35] are often used to predict primary hardness, which is the most important of the mechanical properties of materials. In our case, the coefficients take the maximum values for $\mathrm{Co}_{2} \mathrm{H}$ and $\mathrm{Co}_{3} \mathrm{H}$, compared to $\mathrm{CoH}$. We expect these materials to have improved hardness.

In addition, Shear modulus, Young modulus, Poisson coefficient and Debye temperature vary non-monotonically with hydrogen concentration in unit cell for the systems studied.

Fragile/ductile behavior is one of the important mechanical features, which is related, in particularly, to their ability to compress and reversible fracture. Here, the Pugh indicator (G/B ratio) [36] and the so-called machinability index $\mu_{\mathrm{M}}=\mathrm{B} / \mathrm{C}_{44}$ [37] have been used to measure the malleability. As is known empirically, if $\mathrm{G} / \mathrm{B}<0.5$, a material behaves ductile, and if $\mathrm{G} / \mathrm{B}>0.5$, a material has a brittleness. For $\mathrm{Co}, \mathrm{Co}_{2} \mathrm{H}, \mathrm{Co}_{3} \mathrm{H}$ and $\mathrm{CoH}, \mathrm{G} / \mathrm{B}$ equal to $0.58,0.59,0.53$ and 0.33 respectively, that mean that the systems $\mathrm{Co}, \mathrm{Co} 2 \mathrm{H}$ and $\mathrm{Co} 3 \mathrm{H}$ are fragile, but $\mathrm{CoH}$ behaves ductile.

In other hand, the values of $\mu_{\mathrm{M}}$ are 1.99, 1.48, 1.99 and 2.16 for $\mathrm{Co}$, $\mathrm{Co}_{3} \mathrm{H}, \mathrm{Co}_{2} \mathrm{H}$ and $\mathrm{CoH}$ respectively, when we can see that $\mathrm{CoH}$ have the maximal malleability, which is qualitatively correlated with $\mathrm{G} / \mathrm{B}$ values indicating that $\mathrm{CoH}$ should be the most ductile material in the series.

On the other hand, Poisson's ratio $v$ is another indicator of brittle/ ductile behavior, for brittle covalent materials its values are low $(\sim 0.1)$, but for ductile metallic materials is typically $\sim 0.33$ [33]. In our case The Poisson's ratio vary between 0.25 and 0.35 (Table 3), when $\mathrm{CoH}$ has the maximum value, so it can be concluded that the $\mathrm{Co}, \mathrm{Co}_{3} \mathrm{H}, \mathrm{Co}_{2} \mathrm{H}$ systems are less ductile than $\mathrm{CoH}$.

\section{Band structure}

The electronic band structures of the systems $\mathrm{Co}, \mathrm{Co}_{3} \mathrm{H}, \mathrm{Co}_{2} \mathrm{H}$ and $\mathrm{CoH}$ are computed at the optimized lattice Parameters within the GGA approximation for all configurations and with spin up and spin down electronic orientation. Figure 2 shows the computed energy band structure along the high symmetry directions in the Brillouin for $\mathrm{Co}, \mathrm{Co}_{3} \mathrm{H}, \mathrm{Co}_{2} \mathrm{H}$ and $\mathrm{CoH}$ systems. In view on this figures, it seen that the band structures (BS) of these configurations at the Fermi energy $\left(E_{F}\right)$ level are thickly populated by overlapping valence band (VB) and conduction band $(\mathrm{CB})$ states, revealing a metallic nature for the four systems studied (no energy band gap).

These results lead us to say that the systems $\mathrm{Co}, \mathrm{Co}_{3} \mathrm{H}, \mathrm{Co}_{2} \mathrm{H}$ and $\mathrm{CoH}$ are metals, where the introduction of hydrogen in a low concentration has no effect on the metallic nature of cobalt.

\section{Density of states}

Determination of electronic proprieties of solid requires the knowing of the energy distribution of the valence and conduction bands electrons [38].

In this paper, the density of states (DOS) was determined in order to analyze the electronic structure variances when the low concentration hydrogen was introduced into the Co. That's why we have calculated the total and partial densities of states (DOSs) with potential exchange correlation PBE-GGA of systems studied using the calculated structural data presented in Table 1. They are displayed in Figure 3. The calculated Total DOS and partial of $\mathrm{Co}, \mathrm{Co}_{3} \mathrm{H}, \mathrm{Co}_{2} \mathrm{H}$ and $\mathrm{CoH}$ show that in all compounds studied, the metallic behavior is observed without space between the valence band and the conduction band and the Fermi level is crossed with a strong intensity mainly by the element Co.

Along the graphs accompanying presented the density of state for $\mathrm{Co}, \mathrm{Co}_{3} \mathrm{H}, \mathrm{Co}_{2} \mathrm{H}$ and $\mathrm{CoH}$ respectively. There is a gradual transformation of the electronic structure when hydrogen is introduced in the cobalt matrix. But it is clearly that the characters of $\mathrm{d}$-Co states are dominant in all compounds. For $\mathrm{Co}_{3} \mathrm{H}$, we can see the turmoil existing in Dos, but generally maintained the general form for Co except the region newly apparent between $-12.5 \mathrm{ev}$ and $-6.47 \mathrm{ev}$. For $\mathrm{Co}_{2} \mathrm{H}$ this region become very clearly between $-11.72 \mathrm{ev}$ and $-7.23 \mathrm{ev}$.

For $\mathrm{CoH}$, we can see the conservation of this region apparent in the total DOS presented between $-12.5 \mathrm{ev}$ and $-6.19 \mathrm{ev}$.

According to the partial DOS obtained in Figure 3, the region existing in $\mathrm{Co}_{3} \mathrm{H}, \mathrm{Co}_{2} \mathrm{H}$ and $\mathrm{CoH}$ respectively in valence band due of $\mathrm{s}-\mathrm{H}$ dominant in this systems. But generally, we can see that the nonsymmetry between the DOSs of spin up and down is existing, this results Lead us to say that the systems $\mathrm{Co}, \mathrm{Co}_{3} \mathrm{H}, \mathrm{Co}_{2} \mathrm{H}$ and $\mathrm{CoH}$ are strong ferromagnetic like the cobalt.

\section{Magnetic moments}

To calculate magnetic properties of the systems $\mathrm{Co}, \mathrm{Co}_{3} \mathrm{H}, \mathrm{Co}_{2} \mathrm{H}$ and $\mathrm{CoH}$, we perform spin polarized calculations. The magnetic moments of this system for every configuration are shown in Table 4 with others results experimental and theory. 
Citation: Merabet N, Riane R, Abdiche A (2018) First-Principle Calculation of Structural, Mechanical, Electronic and Magnetic Properties of Cobalt Sub Hydrides $\mathrm{Co}_{2} \mathrm{H}$ and $\mathrm{Co}_{3} \mathrm{H}$. J Material Sci Eng 7: 463. doi: 10.4172/2169-0022.1000463
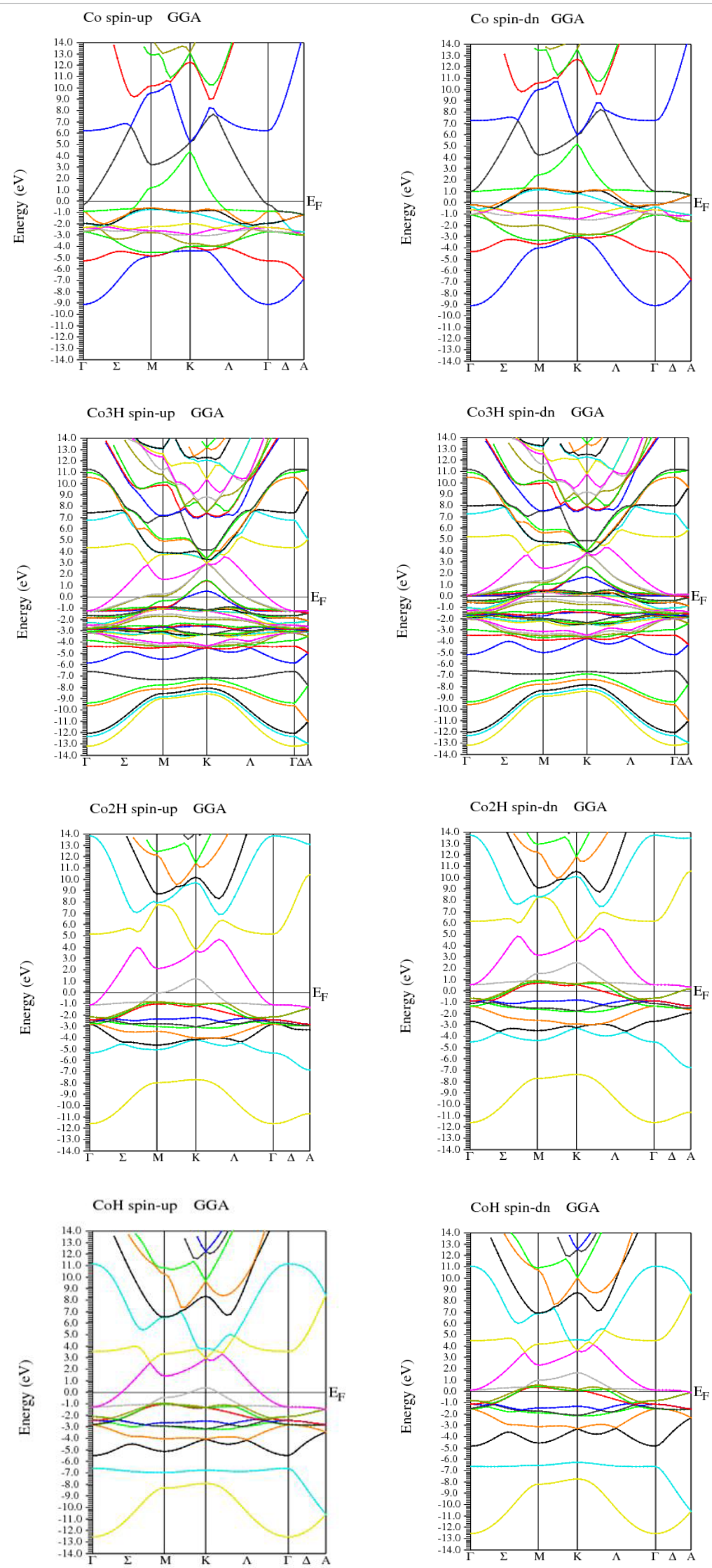

Figure 2: Electronic band structures for minority spins (down) and majority spins (up) of $\mathrm{Co}, \mathrm{Co}_{3} \mathrm{H}, \mathrm{Co}_{2} \mathrm{H}$ and $\mathrm{CoH}$ in $\mathrm{GGA}$ approximations. 
Citation: Merabet N, Riane R, Abdiche A (2018) First-Principle Calculation of Structural, Mechanical, Electronic and Magnetic Properties of Cobalt Sub Hydrides $\mathrm{Co}_{2} \mathrm{H}$ and $\mathrm{Co}_{3} \mathrm{H}$. J Material Sci Eng 7: 463. doi: 10.4172/2169-0022.1000463

Page 6 of 7

\begin{tabular}{|c|c|c|c|c|}
\hline \multicolumn{5}{|c|}{ Spin magnetic moment $\mu\left(\mu_{B}\right)$ of $\mathrm{Co}_{x} \mathrm{H}$ systems } \\
\hline Material & \multicolumn{2}{|c|}{ This work GGA LSDA } & Other Works & Experimental \\
\hline Co & 1.59 & 1.48 & $1.69[9] ; 1.55[21]$ & $1.58[39]$ \\
\hline $\mathrm{Co}_{3} \mathrm{H}$ & 1.50 & 1.386 & - & - \\
\hline $\mathrm{Co}_{2} \mathrm{H}$ & 1.46 & 1.32 & - & - \\
\hline $\mathrm{CoH}$ & 1.28 & 1.11 & - & - \\
\hline
\end{tabular}

Table 4: Effect of the Hydrogen insertion on the magnetic moment in cell of Co system.
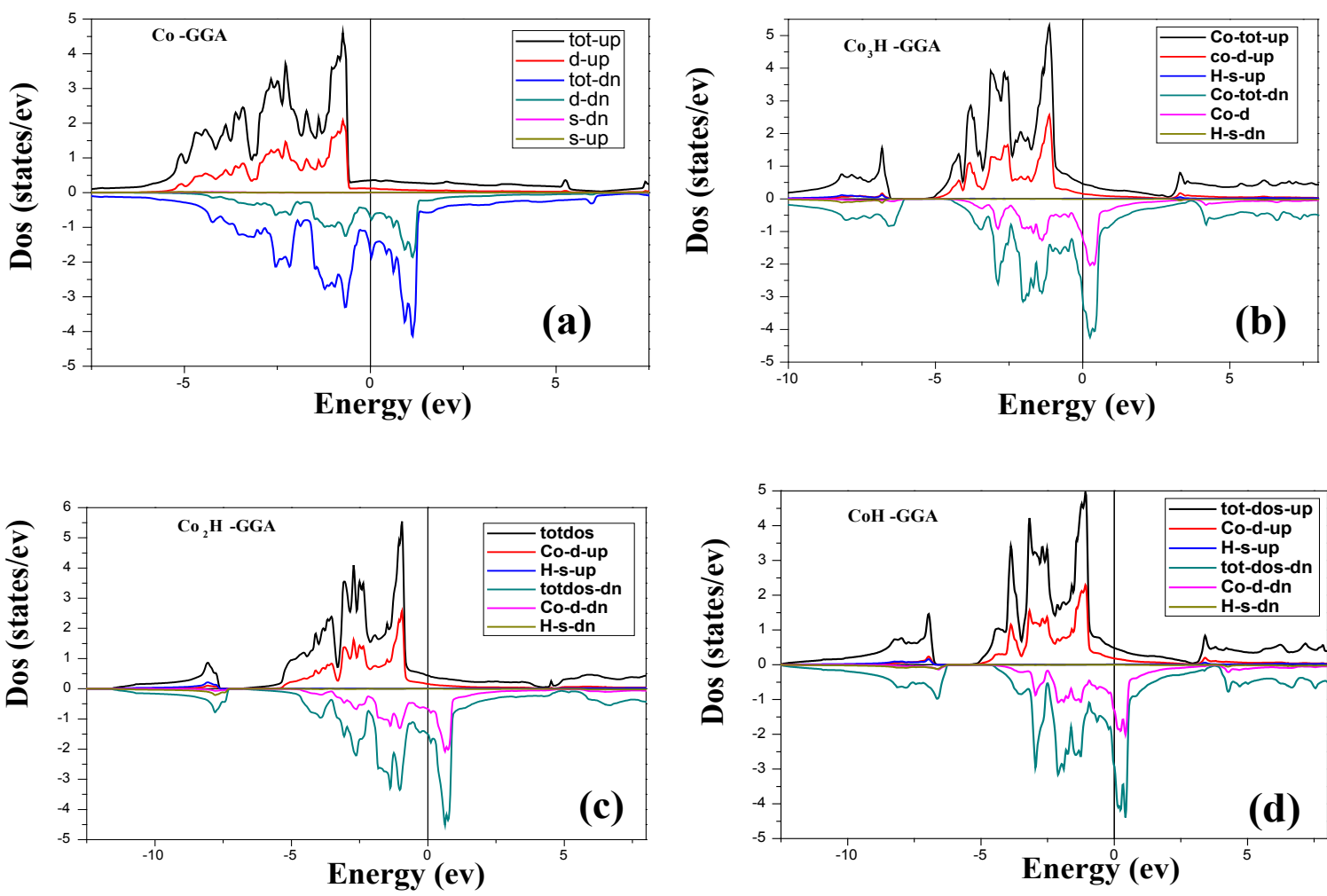

Figure 3: Total and partial density of states for minority spins (down) and majority spins (up) $\mathrm{Co}(a), \mathrm{Co}_{3} \mathrm{H}(\mathrm{b}), \mathrm{Co}_{2} \mathrm{H}(\mathrm{c})$ and $\mathrm{CoH}(\mathrm{d})$ in $\mathrm{GGA}$ approximations

The Table 4 show that The magnetic moment equal to $1.48 \mu_{\mathrm{B}}$ , $1.386 \mu_{\mathrm{B}}, 1.32 \mu_{\mathrm{B}}$ and $1.11 \mu_{\mathrm{B}}$ for respectively $\mathrm{Co}, \mathrm{Co}_{3} \mathrm{H}, \mathrm{Co}_{2} \mathrm{H}$ and $\mathrm{CoH}$ with LSDA approximation and $1.59 \mu_{\mathrm{B}}, 1.50 \mu_{\mathrm{B}} 1.46 \mu_{\mathrm{B}}$ and $1.28 \mu_{\mathrm{B}}$ for respectively $\mathrm{Co}, \mathrm{Co}_{3} \mathrm{H}, \mathrm{Co}_{2} \mathrm{H}$ and $\mathrm{CoH}$ with $\mathrm{GGA}$ approximation .

These values are in good agreement with the experimental data found [39] and the theoretical results [9,21] particularly for Co.

In Figure 4, we traced the magnetic moment as function of the concentration $\mathrm{x}$ of the systems $\mathrm{CoH}_{\mathrm{x}}$, where we observed that the magnetic moment decreases with the increase of the concentration of hydrogen atoms in the unit cell,

This shows that, for each successive insertion of hydrogen atoms, there is a reduction in magnetic moment of the spin of the cluster. This is directly related to the reduction of the character $\mathrm{d}$. This reinforces the previous conclusion that the strong ferromagnetic property remains reserved for the four systems.

\section{Conclusion}

The structural, electronic, magnetic and mechanical properties of the systems $\mathrm{Co}, \mathrm{Co}_{3} \mathrm{H}, \mathrm{Co}_{2} \mathrm{H}$ and $\mathrm{CoH}$ studied in this work, are calculated by using the GGA and LSDA approximations. The results show that the insertion of hydrogen atom in the matrix of cobalt leads to:

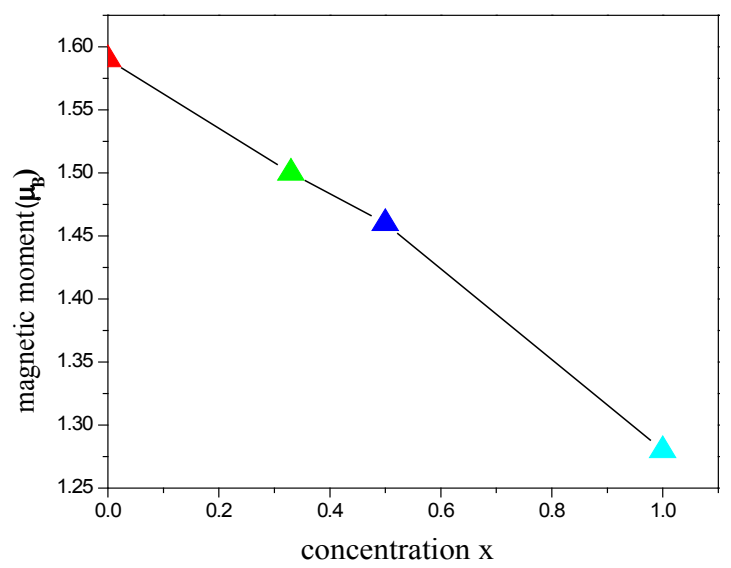

Figure 4: The curve of variation of the magnetic moment as a function of the composition $\mathrm{x}$ of $\mathrm{CoH} x$ in GGA approximation.

- An increase the volume of unit cell of this matrix.

- An increase the bulk modulus.

- A decrease the magnetic moment. 
Citation: Merabet N, Riane R, Abdiche A (2018) First-Principle Calculation of Structural, Mechanical, Electronic and Magnetic Properties of Cobalt Sub Hydrides $\mathrm{Co}_{2} \mathrm{H}$ and $\mathrm{Co}_{3} \mathrm{H}$. J Material Sci Eng 7: 463. doi: 10.4172/2169-0022.1000463

Page 7 of 7

Without these points, we conclude that the sub-hydrides of cobalt are a strong ferromagnetic, when the character d-Co is dominant for all systems studied and they have metallic character, like Co, and this systems are mechanically stable at the ambient conditions.. It is our ambition that these calculations will inspire further experimental research on these systems.

\section{References}

1. Wojciechowska M, Haber J, Lomnicki S, Stoch J (1999) Structure and catalytic activity of double oxide system: Cu-Cr-O supported on MgF2. J Mol Catal A 141: 155.

2. Rao CNR (1989) Annu Rev Phys Chem 40: 291.

3. West R, Hill AF, Fink MJ (2008) Advances in Organometallic Chemistry, Academic Press, USA.

4. Lipshutz BH, Chrisman W, Noson K (2001) Hydrosilylation of aldehydes and ketones catalyzed by [Ph3P(CuH)]6. J Organomet Chem 624: 367-371.

5. Ren Y, Xu X, Sun K, Xu J (2005) A new and effective method for providing optically active monosubstituted malononitriles: selective reduction of $\alpha$, $\beta$-unsaturated dinitriles catalyzed by copper hydride complexes. Tetrahedron: Asymmetry 16: 4010-4014.

6. Veillard A (1991) Ab initio calculations of transition-metal organometallics: Structure and molecular properties. Chem Rev 91: 743-766.

7. Fedotov VK, Antonov VE, Antonova TE, Bokhenkov EL, Dorner B, et al. (1999) Journal of Alloys and Compounds 291: 1-7.

8. Belov MP, Isaev El, Vekilov Yu KH (2011) Ab initio lattice dynamics of $\mathrm{CoH}$ and $\mathrm{NiH}$. Journal of Alloys and Compounds 509: 857-859.

9. Paduani C (2012) Band structure and Fermi surfaces of alternate structural phases of Co and Rh. Solid State Communications 152: 28-33.

10. Yoo CS, Cynn H, Soderlind P, lota VV (2000) New $\beta$ (fcc)-cobalt to $210 \mathrm{GPa}$ Phys Rev Lett 84: 4132-4135.

11. Andersen OK (1975) Linear methods in band theory. Physical Review B. Phys Rev B 12: 3060.

12. Blaha P, Schwarz K, Madsen GkH, Kuasnicka D, Luitz J, et al. An Augmented Plane Wave plus Local Orbitals Program For Calculating Crystal Properties, K Schwarz Technical Universitat, Wien, Austria, 2001.

13. Perdew JP, Burke S, Ernzerhof M (1996) Phys Rev Lett 77: 3865.

14. Perdew J, Wang Y (1992) Phys Rev B 45: 13244.

15. Monkhorst HJ, Pack JD (1976) Phys Rev B 13: 5188.

16. Jamal M (2012) Hex-elastic, http://www.wien2k.at/reg_user/unsupported/ cubic-elast/.

17. Stadler R, Wolf W, Podloucky R, Kresse G, Furthmller J, et al. (1996) Ab initio calculations of the cohesive, elastic, and dynamical properties of CoSi 2 by pseudopotential and all-electron techniques. Phys Rev B 54: 1729.

18. Murnaghan FD (1947) The compressibility of media under extreme pressures. Proc. Natl. Acad. Sci. U. S. A. 30: 244-247.
19. Beck PA (1963) Electronic Structure and Alloy Chemistry of the Transition Elements. Interscience Publishers, New York.

20. Nevit MV, Westbrook JH (1977) Intermetallic Compounds, R.E. Krieger Publishing Co, Huntington NY.

21. Neumann GS, Ronald LS, Cohen E (1999) Phys Rev B 60.

22. Schober R, Dederichs H (1979) Elastic Piezoelectric Pyroelectric Piezooptic Electrooptic Constants and Nonlinear Dielectric Susceptibilities of Crystals, Hellwege KH, Hellwege AW (eds.) Landolt Bornstedt,New Series III, Vol. 11a, Springer, Berlin.

23. Shafiq M, Arif S, Ahmad I, Asadabadi SJ, Maqbool M, et al. (2015) Elastic and mechanical properties of lanthanide monoxides. Journal of Alloys and Compounds 618: 292-298.

24. Wallace DC (1970) Thermoelastic theory of stressed crystals and higher-order elastic constants. Solid State Phys 25: 301-404.

25. Born M, Huang K (1956) Dynamical Theory of Crystal Lattices. Clarendon press.

26. Brazhkin VV (2007) High-pressure synthesized materials: treasures and hints High Pressure Res 27: 333-351.

27. Gilman JJ (2003) Electronic Basis of the Strength of Materials (Cambridge University Press: Cambridge, UK).

28. Haines J, Leger JM, Bocquillon G (2001) Synthesis and design of superhard materials. Ann Rev Mater Res 31: 1.

29. Mehl MJ, Barry BM, Papaconstantopoulos DA (1995) Intermetallic Compounds: Principle and Practice, Volume I: Principles, Westbrook JH, Fleischeir RL (eds.) John Wileyand Sons, London, Ch. 9, pp: 195-210.

30. Sun Z, Music D, Ahuja R, Li S, Schneider JM (2004) Bonding and classification of nanolayered ternary carbides. Phys. Rev. B 70: 508.

31. Anderson OL (1963) A simplified method for calculating the Debye temperature from elastic constants. J Phys Chem. Solids 24: 909-917.

32. Schreiber E, Anderson OL, Soga N (1973) Elastic Constants and Their Measurements, McGraw-Hill.

33. Haines J, Leger JM, Bocquillon G (2001) Synthesis and design of superhard materials. Ann Rev Mater Res 31: 1-23.

34. Teter DM (1998) Computational alchemy: the search for new superhard materials 23: 22-27.

35. Wu ZG, Chen XJ, Struzhkin VV, Cohen RE (2005) rends in elasticity and electronic structure of transition-metal nitrides and carbides from first principles. Phys Rev B 71: 214103.

36. Pugh SF (1954) Relations between the elastic moduli and the plastic properties of polycrystalline pure metals. Phil Mag 45: 823-843.

37. Sun Z, Music R, Ahuja JM, Schneider (2005) Theoretical investigation of the bonding and elastic properties of nanolayered ternary nitrides. Phys Rev B 71 : 193402.

38. Chelikowsky JR, Jin A (1989) Phys Rev B 40: 96644.

39. Meyer HP, Sucksmith W (2007) Proc R Soc London Ser. A 207: 427-1951 